ISSN: $2355-2158$

DOI:

Cite this as:

Effendi, Arief Burhan, Yunianto, Rahaditya. Implementasi Diversity Program Bagi Tenaga Kerja Penyandang

Disabilitas Pada Pt. Wangta Agung Kota Surabaya. Indonesian Journal of Disability Studies (IJDS). 2017: Vol.

04(02): pp. 96-103.

\title{
Implementasi Diversity Program Bagi Tenaga Kerja Penyandang Disabilitas Pada PT. Wangta Agung Kota Surabaya
}

\author{
${ }^{1 *}$ Arief Burhan Effendi, ${ }^{2}$ Rahaditya Yunianto \\ ${ }^{1,2}$ Fakultas Ekonomi dan Bisnis Universitas Brawijaya, Indonesia
}

\begin{abstract}
Abstrak: This research discusses the implementation of diversity program at PT. Wangta Agung in Surabaya. This research uses qualitative method by interviewing four employees of the company; two employees with disability and two employees without disability. This research uses observation and interview method. The method of analysis is attitude-based method for employees with disabilities.

The data of this research were collected through observations and interviews. The result of this research is that the company hires employees with disability that support the value of the organization, apply rules, and provide facilities and infrastructure.

The analysis results reveal that the diversity programs are relevant with the employment and organization value for the management of human resource with disabilities. This study shows that the application of diversity program for people with disability on the employees of PT. Wangta Agung in Surabaya has been well managed by the company. The results also show that there is a recruitment system for prospective employees with disabilities.
\end{abstract}

Keywords: Diversity program, People with disability, Organization value

\section{Latar Belakang}

Zaman sekarang banyak penyandang disabilitas membutuhkan bantuan dan dukungan untuk mencapai kualitas hidup serta hak ekonomi yang baik. Menurut data World Report on Disability yang dikeluarkan oleh World Health Organization (2011) bahwa penyandang disabilitas adalah bagian dari kondisi manusia yang kompleks, dinamis, dan multidimensional. Istilah disabilitas yang meliputi gangguan, keterbatasan aktivitas, dan pembatasan partisipasi. Gangguan adalah permasalahan yang dihadapi oleh seseorang berkaitan dengan fungsi tubuhnya. Kemudian, keterbatasan aktivitas adalah keterbatasan dalam melaksanakan tugas dan tindakan, sedangkan keterbatasan partisipasi adalah masalah yang dialami oleh seseorang dalam keterlibatan di lingkungan sosial.

* Corresponding author: Arief Burhan Effendi

arief.bureff@gmail.com

Published online at http://IJDS.ub.ac.id/

Copyright $\odot$ 2017PSLD UB Publishing. All Rights Reserved
Penyandang disabilitas dapat dikategorikan sebagai penyandang disabilitas fisik, penyandang disabilitas mental, serta penyandang disabilitas fisik dan mental. Menurut data yang dikeluarkan oleh World Health Organization pada www.who.int (2016) dinyatakan bahwa ada sekitar satu milyar penyandang disabilitas di seluruh dunia yang terdiri dari penyandang tunarungu atau tunawicara sebanyak 360 juta orang, penyandang tunanetra sebanyak 200 juta orang, penyandang tunadaksa sebanyak 70 juta, dan penyandang tunaganda sebanyak 370 juta orang di seluruh dunia.

Menurut Economic and Social Commision for Asia and The Pacific (ESCAP) United Nations (2016) di Indonesia, saat ini terdapat 6.008.641 penyandang disabiilitas yang terdiri dari menjadi 2.911.189 orang pria dan 3.097.452 orang wanita. Selain itu, menurut Kementerian Sosial Republik Indonesia dalam situs www.kemsos.go.id (2015) mengenai Survey Sosial Ekonomi Nasional yang 
dilaksanakan oleh Biro Pusat Statistik (BPS) menyatakan bahwa jumlah penyandang disabilitas di Indonesia adalah sebesar 6.008.661 orang, dengan rincian sekitar 1.780 .200 orang adalah penyandang tunanetra, 472.855 orang adalah penyandang tunarungu atau tunawicara, 402.817 orang adalah penyandang tunagrahita, 616.387 orang adalah penyandang tuna tubuh, 170.120 orang adalah penyandang disabilitas yang sulit mengurus diri sendiri, serta sekitar 2.401 .592 orang mengalami disabilitas ganda. Klasifikasi berdasarkan distribusi penyandang disabilitas di Indonesia berdasar kelompok umur dinyatakan dalam tabel sebagai berikut:

Tabel 1 Distirbusi Penyandang Disabilitas di Indonesia Berdasar Kelompok Umur

\begin{tabular}{|c|l|c|}
\hline No. & \multicolumn{1}{|c|}{ Umur } & Persentasi \\
\hline 1 & $0-4$ Tahun & $1 \%$ \\
\hline 2 & $5-17$ Tahun & $7,8 \%$ \\
\hline 3 & $18-30$ Tahun & $10,5 \%$ \\
\hline 4 & 31-59 Tahun & $34,8 \%$ \\
\hline 5 & 60 atas Tahun & $45,8 \%$ \\
\hline
\end{tabular}

Sumber: Economic and Social Commision for Asia and The Pacific (ESCAP) United Nations (2016)

Selain yang disebutkan di atas, penyandang disabilitas pernah mengalami kesulitan yaitu masalah keterbatasan, ketidakmampuan, ketidakberdayaan, serta anggapan lain yang cenderung untuk memperoleh persepsi negatif dan mengarah. Klasifikasi berdasarkan distribusi jenis penyandang disabilitas di Indonesia dinyatakan dalam tabel sebagai berikut:

Tabel 2 Distribusi Jenis Penyandang Disabilitas di

\begin{tabular}{|c|l|l|}
\hline \multicolumn{3}{|c|}{ Indonesia } \\
\hline No. & $\begin{array}{c}\text { Jenis } \\
\text { disabilitas }\end{array}$ & Persentase \\
\hline 1 & Fisik & $10,3 \%$ \\
\hline 2 & Visual & $7,9 \%$ \\
\hline 3 & Pendengaran & $2,7 \%$ \\
\hline 4 & Bicara & $6,7 \%$ \\
\hline 5 & $\begin{array}{l}\text { Mengingat / } \\
\text { konsentrasi }\end{array}$ & $29,6 \%$ \\
\hline 6 & $\begin{array}{l}\text { Tidak bisa } \\
\text { mengurus } \\
\text { diri }\end{array}$ & $2,8 \%$ \\
\hline 7 & Ganda & $40 \%$ \\
\hline
\end{tabular}

Sumber: Economic and Social Commision for Asia and The Pacific (ESCAP) United Nations (2016)

Banyaknya jumlah penyandang disabilitas di dunia maupun di Indonesia tidak membuat penyandang disabilitas otomatis mempunyai akses dalam bidang pekerjaan. Tidak adanya akses ke dalam dunia kerja menyebabkan tingginya tingkat pengangguran bagi para penyandang disabilitas. Namun mayoritas penyandang disabilitas bahkan tidak mendapatkan kesempatan untuk memperoleh pekerjaan karena berbagai macam hambatan. Menurut Mcsshane dan Glinow (2005) menyatakan bahwa nilai organisasi dibahas dalam budaya organisasi secara luas dan mendalam bersama dengan orang dalam organisasi. Nilai organisasi harus mempertimbangkan bihavioralis-humanis dan meritokrasi-egalitarian bagi tenaga kerja penyandang disabilitas.

Menurut Robbins dan Judge (2014) program keragaman yang efektif adalah organisasi menggunakan berbagai upaya untuk memanfaatkan keragaman, termasuk kebijakan perekrutan dan pemilihan serta pelatihan dan pengembangan. Tenaga kerja yang efektif, program yang komprehensif mendorong keragaman memiliki tiga komponen yang berbeda. Pertama, mengajarkan manajer tentang kerangka hukum untuk peluang kerja yang setara dan mendorong perlakuan yang adil dari semua orang tanpa memandang karakteristik demografik. Kedua, mengajarkan manajer bagaimana tenaga kerja yang beragam lebih mampu melayani pasar yang beragam dari pelanggan dan klien. Ketiga, menumbuhkan praktik pengembangan pribadi yang membawa keterampilan dan kemampuan semua pekerja, mengakui bagaimana perbedaan dalam perspektif dapat menjadi cara yang berharga untuk meningkatkan kinerja untuk semua orang.

Terdapat beberapa perusahaan yang masih mau menaruh perhatian pada fenomena seperti ini. Perusahaan sudah menyediakan fasilitas yang dapat dimanfaatkan oleh tenaga kerja, terutama tenaga kerja penyandang disabilitas. Dengan Demikian, karyawan difabel dan nondifabel dapat bekerja sama dengan baik 


\section{Tinjauan Teoritis}

Pembahasan dapat terdiri dari beberapa sub bab. Pembahasan meliputi kerangka berpikir, metodologi penelitian, pengumpulan data, pengolahan data, serta analisa hasil dan pembahasan.

\subsection{Pengertian Manajemen Sumber Daya Manusia}

Menurut Torrington (2008) menyatakan bahwa manajemen sumber daya manusia (MSDM) adalah dasar dari semua aktivitas manajemen, tetapi bukan dasar dari semua aktivitas bisnis. Perubahan angkatan kerja juga diimbangan dengan perubahan hukum serta kebutuhan kerja. Oleh karena itu, kegiatan manajemen sumber daya manusia pula harus terus berubah dan berkembang.

\subsection{Tenaga Kerja Penyandang Disabilitas}

Menurut Undang-Undang Nomor 13 Tahun 2003 bahwa tenaga kerja penyandang disabilitas adalah tenaga kerja yang mempunyai kelainan fisik dan mental namun mampu melakukan kegiatan secara layak, serta melakukan pekerjaan baik di perusahaan dalam hubungan kerja internal maupun eksternal guna menghasilkan barang dan jasa. Tenaga kerja penyandang disabilitas dapat dikategorikan dalam beberapa klasifikasi berdasarkan jenis disabilitasnya antara lain seperti pada Tabel 3 .

Tabel 3 Klasifikasi Jenis Penyandang Disabilitas

\begin{tabular}{|c|c|c|}
\hline Nama & $\begin{array}{c}\text { Jenis } \\
\text { disabilitas }\end{array}$ & Pengertian \\
\hline$\frac{\text { Tunanetra }}{\text { (blind })}$ & $\begin{array}{c}\text { Disabilitas } \\
\text { fisik }\end{array}$ & $\begin{array}{c}\text { tidak dapat } \\
\text { melihat }\end{array}$ \\
\hline$\frac{\text { Tunarungu }}{(\text { deaf })}$ & $\begin{array}{c}\text { Disabilitas } \\
\text { fisik }\end{array}$ & $\begin{array}{c}\text { tidak dapat } \\
\text { mendengar } \\
\text { atau kurang } \\
\text { dalam } \\
\text { mendengar }\end{array}$ \\
\hline$\frac{\text { Tunawicara }}{\text { (speech }}$ & $\begin{array}{c}\text { Disabilitas } \\
\text { fisik }\end{array}$ & $\begin{array}{c}\text { tidak dapat } \\
\text { berbicara }\end{array}$ \\
\hline$\frac{\text { Tunadaksa }}{\text { (physical) }}$ & $\begin{array}{c}\text { Disabilitas } \\
\text { fisik }\end{array}$ & $\begin{array}{c}\text { disabilitas } \\
\text { tubuh }\end{array}$ \\
\hline$\frac{\text { Tunagrahita }}{\text { (autism) }}$ & Disabilitas & $\begin{array}{c}\text { disabilitas } \\
\text { pikiran atau } \\
\text { lemah daya } \\
\text { tangkap }\end{array}$ \\
\hline
\end{tabular}

Cite this as:

Effendi, Arief Burhan, Yunianto, Rahaditya. Implementasi Diversity Program Bagi Tenaga Kerja Penyandang Disabilitas Pada Pt. Wangta Agung Kota Surabaya. Indonesian Journal of Disability Studies (IJDS). 2017: Vol. 04(02): pp. 96-103.

\begin{tabular}{|c|c|c|}
\hline Tunaganda & $\begin{array}{c}\text { Disabilitas } \\
\text { fisik dan } \\
\text { mental }\end{array}$ & $\begin{array}{c}\text { penderita } \\
\text { disabilitas } \\
\text { lebih dari satu }\end{array}$ \\
kedisabilitasan \\
\hline
\end{tabular}

Sumber : Undang-Undang Nomor 8 Tahun 2016

Berdasarkan peraturan pemerintah tenaga kerja Republik Indonesia, tenaga kerja penyandang disabilitas memiliki hak untuk memperoleh pekerjaan dan tempat pada suatu jabatan atau posisi pekerjaan tertentu. Perusahaan dapat mengacu pada model manajemen sumber daya Manusia (MSDM) berbasis sikap menurut Macy (1996) dalam Gambar 1.1 misalnya memiliki atau ingin mempekerjakan karyawan dengan penyandang disabilitas.

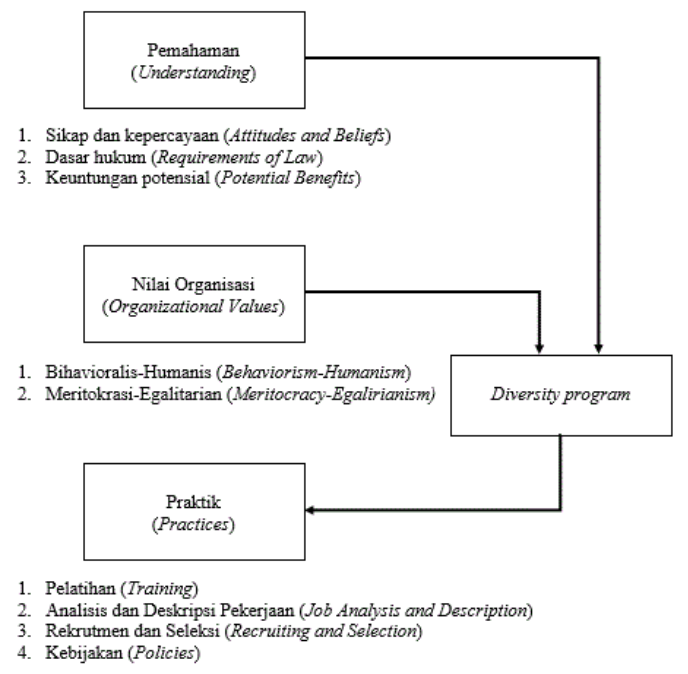

Gambar 1 Model Berbasis Sikap untuk Ketenagakerjaan Disabilitas

Sumber: Macy, Granger (1996) Accommodating Employee with Disabilities: A Matter of Attitude. Journal of Managerial Issues P 79 Vol. 8 No. 1. Pittsburg State University, Inc. United States of America.

\subsection{Budaya Organisasi}

Menurut Mcsshane dan Glinow (2005) menyatakan bahwa nilai organisasi dibahas dalam budaya organisasi secara luas dan mendalam bersama dengan orang dalam organisasi. Menurut Robbin dan Judge (2013) budaya organisasi merujuk kepada suatu sistem yang diselenggarakan oleh anggota. Terdapat dua jenis nilai yaitu nilai terminal dan instrumental. Nilai terminal adalah nilai terakhir yang diinginkan. Organisasi mungkin 
mengadopsi salah satu nilai terminal yaitu kualitas, tanggung jawab, inovasi, keunggulan, ekonomi, moralitas, dan profitabilitas. Nilai instrumental adalah modus yang diinginkan atau jenis perilaku yang menganjurkan organisasi untuk bekerja keras, menghormati tradisi, menjadi kreatif, berani dan jujur, serta mempertahanskan standar yang tinggi.

\subsection{Diversity program}

Implementasi diversity program membutuhkan konsistensi dan dukungan dari kepemimpinan, serta kesediaan dan kesepakatan setiap anggota perusahaan untuk mengubah budaya kerja agar lebih ramah terhadap perbedaan dalam keragaman. Menurut Robbin dan Judge (2014) menyatakan bahwa organisasi menggunakan berbagai upaya untuk memanfaatkan keragaman, termasuk perekrutan dan pemilihan kebijakan. Praktik pelatihan dan pengembangan tenaga kerja yang efektif dan program yang komprehensif untukmendorong keragaman yang memiliki tiga komponen yang berbeda. Pertama, mengajarkan manajer tentang kerangka hukum tentang peluang kerja yang setara dan mendorong perlakuan yang adil bagi semua terlepas dari karakteristik demografis. Kedua, mengajarkan manajer tentang keragaman tenaga kerja akan lebih mampu melayani pasar yang beragam dari pelanggan dan klien. Ketiga, mendorong praktik pengembangan pribadi yang meningkatkan keterampilan dan kemampuan untuk semua pekerja, mengakui perbedaan dalam perspektif positif sehingga dapat menjadi cara yang berharga untuk meningkatkan kinerja semua karyawan.

\section{METODE PENELITIAN}

\subsection{Metode Pengumpulan Data}

Menurut Zikmund (2013) penelitian kualitatif bisnis adalah penelitian yang menangani tujuan bisnis dengan teknik yang memungkinkan peneliti untuk menghasilkan interpretasi yang rinci tentang fenomena pasar tanpa bergantung pada pengukuran numerik. Berdasarkan definisi yang dipaparkan ahli tersebut dapat disimpulkan bahwa penelitian kualitatif adalah mengintepretasikan secara

Cite this as:

Effendi, Arief Burhan, Yunianto, Rahaditya. Implementasi Diversity Program Bagi Tenaga Kerja Penyandang Disabilitas Pada Pt. Wangta Agung Kota Surabaya. Indonesian Journal of Disability Studies (IJDS). 2017: Vol. 04(02): pp. 96-103. logis fenomena dari subjek bisnis, bersifat naturalistik dan dilakukan dengan cara berinteraksi langsung dengan informan.

\subsection{Metode Analisis Data}

Metode analisis data adalah proses mencari dan menyusun secara sistematis data yang diperoleh dari hasil wawancara, observasi serta dokumentasi, dengan mengelompokkan data, menjabarkan dalam unit, menyusun pola, dan membuat kesimpulan.

\section{PEMBAHASAN}

\subsection{Hasil Analisis Wawancara}

Dalam menetapkan kebijakan diversity program para karyawan melakukan diskusi tentang pekerjaan sehingga seluruh karyawan mendelegasikan tanggung jawab dan pengambilan keputusan untuk meningkatan kinerja dengan baik. Sebaiknya seluruh karyawan diberikan tingkat prestasi kinerja selama melakukan pekerjaan secara maksimal.

\subsection{Pemahaman (Understanding)}

Sehingga Permasalahan yang muncul dalam hasil wawancara dengan informan dapat dijabarkan sebagai berikut.

1. Sikap dan Kepercayaan(Attiudes and Beliefs)

Terdapat training khusus bagi tenaga kerja penyandang disabilitas tentang cara memproduksi sepatu pada masa magang dalam perusahaan. Tenaga kerja penyandang disabilitas diharapkan dapat mandiri dan bertanggung jawab dalam melakukan pekerjaan. Tenaga kerja penyandang disabilitas memperoleh pembekalan yang diberikan perusahaan. Seluruh karyawan menjadi satu sehingga terkontrol dalam memberikan arahan dan memotivasi serta bertanggung jawab untuk dapat meningkatan kinerja yang diberikan perusahaan. Karyawan tunarungu sudah memiliki niat, kemampuan, dan ketrampilan yang diberikan saat training di bidang masing-masing. Hal ini, untuk memajukan perusahaan yang telah mendukung 
tersedianya program kegiatan terhadap tenaga kerja penyandang disabilitas.

\section{Dasar hukum (Requirements of Law)}

Dibutuhkan kebijakan dan aturan untuk akses penyandang disabilitas. Perusahaan wajib memberi kesempatan kerja bagi para tenaga kerja penyandang disabilitas yang mampu dan berniat serta terampil dalam bidang masing-masing. Perusahan memberikan fasilitas perlengkapan sarana, prasana, dan peraturan untuk tenaga kerja penyandang disabilitas agar memperoleh pekerjaan. Penyediaan kebijakan untuk tenaga kerja penyandang disabilitas memberikan motivasi kepada tenaga kerja penyandang disabilitas. Hal ini, diperlukan agar tenaga kerja penyandang disabilitas dapat bekerja dengan baik. Kalau tidak tahu cara menjahit dengan produksi sepatu, karyawan difabel diberi training keterampilan. Seharusnya tenaga kerja penyandang disabilitas wajib mengikuti training khsusus tenaga ahli jahit pada masa magang dalam perusahaan agar tenaga kerja penyandang disabilitas menjadi profesional. Sebaiknya karyawan difabel wajib saling bekerja sama dengan karyawan nondifabel.

\section{Kuntungan potensial (Potential Benfits)}

Perusahaan seharusanya menyusun kriteria kemampuan tenaga kerja penyandang disabilitas dan disesuaikan dengan minat dalam perusahaan. Hal ini, dikarenakan mendorong tenaga kerja penyandang disabilitas untuk maju dalam meningkatkan kinerja. Sehinggga, tenaga kerja penyandang disabilitas mendapatan penilaian kinerja mengenai pekerjaaan. Maka dari itu, perusahan memberikan penilaian tingkat kinerja kepada tenaga kerja penyandang disabilitas. Dengan seluruh karyawan saling bersaing untuk melakukan pekerjaan dalam perusahaan. Seluruh karyawan dapat bersaing untuk memberikan keberhasilan masingmasing secara jujur dan tidak merugikan perusahan.

\subsection{Nilai Organisasi (Oganizational Values)}

Dalam mengambarkan lebih detail nilai orgnisasi untuk PT. Wangta Agung Kota
Surabaya yang ada lapangan pekerjaan serta meningkatkan objektifitas dalam penelitian ini, hasil wawancara yang akan dicantumkan telah melalui proses penyusunan data, sehingga permasalahan yang tampak dalam hasil analisis informan dengan pencarian data dan informasi telah selesai dilakukan saat wawancara. Hal ini, menjelaskan lebih detail mengenai kondisi nilai organisasi pada PT. Wangta Agung Kota Surabaya khususnya situasi yang dengan tujuan penelitian yaitu Bihavioralis-Humanis dan MeritokrasiEgalitarian. Dapat dilihat sebagai berikut.

\section{Bihavioralis-Humanis (Behavioral- Humanism)}

Calon tenaga kerja panyandang disabilitas bisa menjadi karyawan untuk bekerja dalam perusahaan. Hal ini, disebabkan tenaga kerja penyandang disabilitas memiliki tingkat kemampuan dan bakat. Dengan itu, tenaga kerja penyandang disabilitas secara aktif perlu diberikan motivasi dalam kinerja. Sangat senang ketika pekerjaan berjalan lancar. Setiap kebijakan yang untuk peraturan memberi fasilitas training kepada tenaga kerja penyandang disabilitas. Karyawan tunarungu memiliki kemampuan bakat dan semangat untuk memperoleh kinerja mencapai perusahaan. Pentingnya wawancara dengan karyawan tunarungu untuk mengetahui kecocokan dengan ketrampilan bidang masing-masing.

\section{Meritokrasi-Egalitarian (Meritocray- Egalitarianism)}

Perusahaan mendukung seluruh karyawan bekerja sama dalam tim perusahaan. Dengan ini, kebijakan serikat pekerja harus secara aktif mendorong tenaga kerja penyandang disabilitas untuk bergabung dengan karyawan non-difabel untuk masa kegiatan training kerja yang diberikan perusahaan. Seperlunya kebijakan tersedia saling kerjasama dengan tim untuk karyawan difabel. Seluruh karyawan memberikan informasi pada penyandang disabilitas melalui tulisan atau pengumuman dalam perusahaan. Sebagai dukungan perusahaan dalam memberi kesempatan komunikasi untuk karyawan tunarungu dalam berhubungan dengan supervisor, manajer, dan direktur. Oleh itu, diharapkan agar berjalan lancar untuk perusahaan.

Cite this as: 
Perusahaan mewajibkan untuk tidak membedakan antara karyawan non-difabel dan difabel yang diberikan perusahaan. Dikarenakan perusahaan secara aktif mendorong karyawan difabel untuk ikut bekerja pada perusahaan. Oleh karena itu, diharapkan karyawan difabel dapat sukses dalam bekerja pada perusahaan. Ketenagakerjaan khusus penyandang disabiltas diberikan waktu delepan jam dalam sehari bekerja pada perusahaan. Dengan ini, perusahaan memberikan kesempatan kerja yang sama antara karyawan difabel dan nondifabel. Karyawan difabel diberikan kriteria hasil karya yang sama untuk menilai kinerja.

\subsection{Praktk (Practies) menerapkan diversity program}

Untuk mengambarkan lebih detail praktik dalam memperoleh diversity program ini merupakan Manajemen Sumber Daya Manusia (MSDM) untuk ketenagkerjaan disabilitas serta meningkatan objektifitas dalam penelitian ini, hasil wawancara yang akan dicantumkan telah melalui proses penyusunan data, sehingga permasalahan yang tampak dalam hasil analisis informan dengan pencarian data dan informasi telah selesai dilakukan pada saat wawancara. Hal ini, menjelaskan lebih detail mengenai kondisinya dalam praktik memperoleh diversity program di lapangan khususnya situasi dengan tujuan penelitian yaitu pelatihan, analisis dan deskripsi pekerjaan, rekrutmen dan seleksi, serta kebijakan. Dapat dilihat sebagai berikut.

\section{Pelatihan (Training)}

Fasilitas yang diberikan kesempatan untuk karyawan difabel dengan mengikuti pelatihan produksi dari tenaga profesi ahli dalam perusahaan. Melalui cara ini, seharusnya dapat mendukung menyediakan karyawan difabel melakukan kerja dalam perusahaan. Dengan adanya training bagi ketenagakerjaan disabilitas terjadi peningkatan kinerja karena memberdayakan penyandang disabilitas. Seluruh karyawan diberikan training bahasa isyarat yaitu SIBI (Sistem Isyarat Bahasa Indonesia) dan BISINDO (Bahasa Isyarat Indonesia) atau didampingi memperoleh pendamping (Volunteer) dan penerjemahan bahasa isyarat untuk penyandang tunarungu kerjasama dengan

Cite this as:

Effendi, Arief Burhan, Yunianto, Rahaditya. Implementasi Diversity Program Bagi Tenaga Kerja Penyandang Disabilitas Pada Pt. Wangta Agung Kota Surabaya. Indonesian Journal of Disability Studies (IJDS). 2017: Vol. 04(02): pp. 96-103. pusat layanan juru isyarat. Dengan ini dikarenakan agar lancar dalam berkomunikasi bahasa isyarat atau lisan dengan karyawan tunarungu. Seharusnya perusahaan perlu diberikan kesempatan berkomunikasi bagi karyawan tunarungu. Untuk informasi silahkan hubungi pusat layanan juru isyarat melalui situs www.plj.com.

\section{Analisis dan Deskripsi (Job Analysisand Description)}

Ketenagakerjaan khusus penyandang disabilitas diberikan evaluasi oleh pengawas dalam perusahaan. Hal ini, menunjukan perhatian perusahaan pada karyawan difabel untuk melakukan pekerjaan. Tenaga kerja penyandang disabilitas perlu melakukan evaluasi tentang kinerja. Hal yang sama pada setiap aturan perusahaan untuk dilakukan evaluasi memperoleh karyawan difabel. Seharusnya manajer dan para karyawan difabel dan non-difabel yang diberikan kesempatan kerja melakukan peningkatkan kinerja dalam perusahaan. Dengan ini, aturan harus relevan dan sesuai dengan visi dan misi perusahaan.

\section{Rekrutmen dan Seleksi (Recruiting and Selection)}

Ketenagakerjaan khusus penyandang disabilitas wajib mengikuti training selama masa magang dan bekerja dalam perusahaan. Sehingga, calon tenaga kerja penyandang disabilitas dapat memiliki peningkatan kecakapan dan kemampuan memperoleh kinerja. Dengan adanya pelatihan tersebut maka persyaratan yang ada dapat terpenuhi. Perlu di setiap periode perusahaan memberikan infromasi kepada penyandang disabilitas sebagai calon tenaga kerja yang ingin mengikuti seleksi karyawan difabel. Dengan ini, perusahaan wajib memberikan kebijakan akses difabel memperoleh fasilitas perlengkapan serta sarana, prasana dan peraturan terhadap calon tenaga kerja penyandang disabilitas yang diberikan perusahaan. Sebagai pengelolaan dalam merekrut calon tenaga kerja penyandang disabilitas untuk memperoleh pekerjaaan. Salah satu seluruh karyawan memakai tulisan atau bahasa isyarat dengan karyawan tunarugu dalam perusahaan. Dengan ini, sehingga agar lancarkan komunikasi secara baik. 
Dikarenakan tergantung pada karyawan tunarungu sulit berkomunikasi dengan karyawan lain.

\section{Kebijakan (Policies)}

Perlu dibutuhkan fasilitas yang mendukung akses kepada tenaga kerja penyandang disabilitas dalam perusahaan. Dikarenakan perusahaan tidak memiliki kebijakan fasilitas perlengkapan serta sarana, prasana, dan peraturan untuk tenaga kerja penyandang disabilitas yang melakukan pekerjaan dalam perusahaan. Dikarenakan kinerja karyawan difabel dapat berkurang. Perusahaan mewajibkan untuk tidak membedakan karyawan non-difabel dan difabel dalam perusahaan, serta seluruh karyawan harus mematuhi 5R yaitu singkatan dari ringkas, rapi, resik, rawat, dan rajin yang diberikan perusahaan. Peraturan serta layanan yang ada dilakukan tanpa membeda-bedakan karyawan difabel dan non-difabel. Selain itu karyawan difabel dan non-difabel bisa dikenali ketika masuk kerja.

\section{Penutup}

Hal tersebut, membuat PT. Wangta Agung Kota Surabaya mudah dijangkau dan sering dikunjungi. Berdasarkan hasil dari penelitian dan pembahasan dapat ditarik kesimpulan sebagai berikut:

1. Penilaian pertama dilakukan dengan menilai penyelesaian tugas yang telah dilakukan pada awal tahun. Pada tahap ini dilakukan evaluasi sebanyak satu kali untuk mengingatkan karyawan difabel akan banyaknya beban kerja yang masih harus diselesaikan sebagai analisis hambatan dalam menyelesaikan tugasnya. Poin penting yang dijadikan penilaian adalah seberapa banyak target yang telah ditentukan pada awal tahun. Contoh konkrit adalah pada bagian purchasing dengan melihat seberapa banyak pesanan yang terlaksana dengan melihat sebeberapa banyak pesanan yang sudah terlaksana dan belum pula terlaksana. Penilai kedua dinilai secara langsung dari PT. Wangta Agung Kota Surabaya. Penilaian ini lebih dititik beratkan kepada kesesuaian karyawan dengan pekerjaan atau job desc dari karyawan difabel tersebut. Beberapa poin yang dijadikan acuan dalam penilaian ini adalah motivasi, komunikasi, job desc, leadership, kreativitas, dan lain-lain.

2. Perusahaan masalah tidak terdapat fasilitas khusus bagi penyandang disabilitas utamanya dalam keselamatan kerja dari perusahaaan, mekanisme perlindungan kerja tertentu pada tenaga kerja penyandang disabilitas, tidak adanya perbedaan rekrutmen yang dilakukan untuk calon karyawan khususnya bagi penyandang disabilitas, tidak terdapat program aturan khusus bagi karyawan difabel, dan tidak terdapat fasilitas perlengkapan yang diberikan bagi tenaga kerja penyandang disabilitas.

3. Perusahan beberapa belum maksimal antara lain karyawan berkomunikasi secara langsung atau dengan diadakan meeting pada pihak eksekutif atau manageril perusahaan namun tidak termekanisme perlindungan kerja tertentu para tenaga kerja penyandang disabilitas, sikap sama dan tidak ada perbedaaan dengan non-difabel oleh tenaga kerja penyandang disabilitas pada saat beraktivitas atau bekerja, tenaga kerja penyandang disabilitas melakukan komunikasi dengan bahasa isyarat dan tulisan pada kertas, selain karyawan difabel dan non-difabel dihimbau untuk selalu berjalan kompak sesuai pihak ekskutif atau managerial perusahaan. Dengan itu, perusahaan melarang tindakan kekerasan dalam bekerja dan akan memberikan bimbingan kerja terkait mekanisme perlindungan kerja.

PT. Wangta Agung Kota Surabaya diharapkan dapat segera memotivasi karyawan dalam hal kerja sampai pada output yang dihasilkan penyandang disabilitas, serta mulai merencanakanprogram pelatihan karyawan difabel yang efektif dan berkelanjutan. Selain itu, perlu dilakukan sosialisasi mengenai proses pemberian pengawasan diversity program yang cepat dan mudah kepada seluruh para karyawan non-difabel dan difabel, serta mengadakan kegiatan evaluasi untuk mengedukasi para karyawan tentang program yang akan dilakukan oleh PT. Wangta Agung Kota Surabaya, seperti penyuluhan pemberian pelayanan jasa yang baik, etika sopan santun terhadap pengunjung, dan penampilan.

Penilaian yang telah dilakukan tentu harus dilakukan sedikit modifikasi untuk

Cite this as:

Effendi, Arief Burhan, Yunianto, Rahaditya. Implementasi Diversity Program Bagi Tenaga Kerja Penyandang Disabilitas Pada Pt. Wangta Agung Kota Surabaya. Indonesian Journal of Disability Studies (IJDS). 2017: Vol. 04(02): pp. 96-103. 
menyesuaikan dengan kebudayaan dan keperluan setiap karyawan khususnya bagi difabel. Berdasarkan hasil analisis maka diharapkan bagi penelitian selanjutnya untuk menggunakan informan yang berpengaruh meningkatkan kinerja untuk para pegawai dengan harapan penelitian ini dapat lebih berkembang. Informan data tersebut yaitu mengenai lingkungan ketengakerjaan, budaya organisasi, serta budaya disiplin kerja dalam memperoleh diversity program yang dapat meningkatkan kinerja karyawan.

\section{Daftar Pustaka}

Barak, Michalle E Mor. (2014). Managing Diversity Toward Globally Inclusive Workplace Third Edition. SAGE Publication, Inc. United States Of America.

Economic and Social Commission for Asia and the Pacific (ESCAP) United Nations Building. (2016). Disability at a Glance 2015 Strengthening Employment Prospects for Persons with Disabilities in Asia and the Pacific. ESCAP United Nations Publication. Thailand.

Kementerian Sosial Republik Indonesia. (2015). "Pelayanan Penyandang Disabilitas Dalam Menggunakan Berbagai Sarana Aksebilitas"http://www.kemsos.go.id/modules. php? name $=$ News\&file $=$ article $\&$ sid $=18765$. Diakses pada Hari Minggu, 17 Juli 2016 pukul 20.00 WIB.

Macy, Granger. (1996). Accommodating Employees With Disabilities: A matter Of Attitude. Journal Of Managerial Issues, Vol 8, No. 1. Published by Pittburg State university,Inc. United States of America.

McShane, Steven L and Glinow, Von. (2005). Organizational Behavior $3 c$ international Edition. Published by McGraw-Hill/Irwin. New York, United States of America.

Mullins, Laurie J. (2010). Management \& Organisational Behaviour Ninth Edition. Pearson Education Limited. Rotolito Lombarda, Italy.
Nislon, Julie. (1997). Developing a Diversity program. Healthcare Excutive. 1997 July/August. Vol. 12 Issue 4. Published by ProQuest LLC. United States America.

Robbins, Stephen $\mathrm{P}$ and Judge, Timothy A. (2014). Essentials of organizational behavior Twelfth Edition. Pearson Education, Inc. United States of America.

Siniwi, Ratri M. Jakartaglobe. (2016). "New Network Promotes Employment of People With Disabilities". http://jakartaglobe.id/businessnew-networkpromotes-employment-people-disabilities/. Diakses pada Hari Kamis, 21 Desember 2016 pukul 13.00 WIB

Tringgton, Derek., Hall, Laura., and Taylor, Stephen. (2008). Seventh Edition Human Resource Management. Pearson Education Limited. Matev Croms Artes Graficas, Spain.

Undang-Undang Negera Republik Indonesia Nomor 8 Tahun 2016 tentang Penyandang Disabilitas.

Undang-Undang Negera Republik Indonesia Nomor 13 Tahun 2003 tentang Ketenagakerjaan.

World Health Organization, (2011). World Report On Disability. Publications of the World Health Organization (WHO). Acces in (www.who.int) or purchased from WHO Press. Malta.

World Health Organization. (WHO). (2016). "Better Health for People with Disabilities: Infographic"

http://www.who.int/disabilities/infographic/en/ . Diakses pada Hari Jumat, 22 Juli 2016 pukul 15.30 WIB.

Zikmund, Wiliam G. Babin, Barry J. Carr, Jon C. And Griffin, Mitch. (2013). Business Research Methods, Ninth Edition, SouthWestern, Cengage Learning. United States of America 